\title{
PENERAPAN METODE ANALISIS NILAI HASIL TERHADAP BIAYA DAN WAKTU PELAKSANAAN PROYEK (STUDI KASUS PEMBANGUNAN ATC TOWER BANDAR UDARA SYUKURAN AMINUDDIN AMIR, DI LUWUK)
}

\author{
Hanafi Ashad ${ }^{1}$, Lambang Basri Said ${ }^{2}$, Umurtullah Dini Hardi ${ }^{3}$
}

\author{
${ }^{1}$ Dosen Jurusan Teknik Sipil Universitas Muslim Indonesia (UMI) \\ Jln. Urip Sumoharjo No.225 Makassar,Tlp.454534.hanafiashad@yahoo.co.id \\ ${ }^{2}$ Dosen Jurusan Teknik Sipil Universitas Muslim Indonesia (UMI) \\ Jln. Urip Sumoharjo No.225 Makassar,Tlp.454534,elbasri_umi@yahoo.com \\ ${ }^{3}$ Mahasiswa Program Pascasarjana Magister Teknik Sipil Umi Makassar \\ Jln. Urip Sumoharjo No.225 Makassar,Tlp.454534.umurtullahdinihardi@gmail.com
}

\begin{abstract}
Abstrak
Permasalahan utama pelaksanaan suatu proyek kostruksi adalah tidak adanya kesesuaian antara biaya, mutu dan waktu.pelaksanaan proyek. Penjadwalan dan pengendalian adalah langkah penting untuk dilakukan agar tujuan pelaksanaan proyek dengan sumberdaya terbatas ini dapat dicapai. Earned Value adalah suatu metode pengendalian yang digunakan untuk mengendalikan biaya dan jadwal proyek secara terpadu. Metode ini memberikan informasi status kinerja proyek pada suatu periode pelaporan dan memberikan informasi prediksi biaya yang dibutuhkan dan waktu untuk penyelesaian seluruh pekerjaan berdasarkan indikator kinerja saat pelaporan. Tujuan penelitian ini adalah mengetahui bagaimana penerapan EVA dalam memperkirakan waktu akhir tahapan penyelesaian proyek. Metode yang digunakan dalam penelitian ini ini adalah deskriptif kualitatif dengan durasi pengerjaan proyek selama 32 minggu. Studi ini mengkaji, waktu penyelesaian proyek tidak sesuai dengan rencana awal jadwal proyek, pada Minggu ke - 1 hingga minggu ke - 7 menunjukkan bahwa nilai PV dan EV sejajar, lalu minggu ke - 8 sampai minggu ke 10 nilai PV lebih besar daripada EV, kemudian Minggu ke - 11 hingga minggu ke - 23 grafik EV lebih tinggi dari PV, lalu untuk minggu ke - 24 hingga minggu ke - 30 nilai PV lebih besar daripada EV dan nilai pekerjaan pada Minggu ke - 31 sampai 32 terhitumg sudah selesai $100 \%$. Prakiraan waktu penyelesaian proyek apabila menggunakan perhitungan komulatif, berdasar minggu ke - 7 adalah 222.63 hari, sedangkan waktu rencana adalah 224 hari. Hal ini menunjukkan bahwa waktu penyelesaian lebih cepat 1.37 hari dari yang direncanakan. Sedangkan apabila kita menggunakan perhitungan tiap minggu, Prakiraan waktu penyelesaian proyek berdasar minggu ke - 7 adalah 239,36 hari, sehingga proyek mengalami keterlambatan $-15,36$ hari.
\end{abstract}

Kata Kunci : Air Traffic Control (ATC), Proyek Konstruksi, Pengendalian Biaya dan Waktu, Konsep Nilai Hasil

\section{PENDAHULUAN}

\subsection{Latar Belakang}

Indonesia merupakan salah satu negara yang luas, secara geografis terbentuk atas ribuan pulau yang tersebar dari Sabang sampai Merauke, serta sangat strategis di kawasan Asia. Dengan jumlah penduduk sekitar 247,43 juta orang (Sumber: Indonesia Population, 2014), saat ini Indonesia mempunyai menara Air Traffic Control hampir disetiap bandar udara di seluruh wilayah NKRI. 
Dalam kajian tentang penulisan ini, maka akan diuraikan teori atau metodologi mengenai penerapan metode analisis nilai hasil (Earned Value Analysis) terhadap biaya dan waktu pelaksanaan proyek terhadap pembangunan Air Traffic Control yang sesuai standart Bandar udara di Indonesia, posisi atau urutan Bandar Udara Syukuran Aminuddin Amir, di Luwuk.

Pada awalnya ATC digunakan secara sederhana (rules of the road), dengan sponsor Konvensi Internasional Eropa untuk Navigasi Udara tahun 1919. Peraturan pertama Lalu Lintas Udara (Air Traffic) diresmikan oleh Amerika Serikat dengan Air Commerce Act (1926). Sekitar 1930, menara kontrol dengan menggunakan radio telah digunakan oleh beberapa bandar udara setempat dan pada 1933 penggunaan instrumen penerbangan dimulai. Tahun 1936, secara resmi generasi pertama system ATC digunakan. ATC, merupakan 4 unit pelayanan yang terdiri: Flight Information Service, Alerting Service, Air Traffic Advisory Service dan Air Traffic Control (ATC) Service. (Air Traffic Control, Wikipedia, 2013 dan FAA, 2012).

Pelayanan Lalu Lintas Udara (ATS : Air Traffic Services), Pelayanan lalu lintas udara adalah pemanduan dan pengaturan pesawat udara yang diberikan ATC (Air Traffic Control) dengan jalur khusus. Tujuan dari pengaturan lalu lintas udara adalah untuk menghindarkan tabrakan antar pesawat udara, menghindarkan pesawat udara yang berada di daerah pergerakan pesawat dengan penghalang lainnya dan terciptanya serta keteraturan lalu lintas udara (Air Traffic Control, Wikipedia, 2013 dan FAA, 2012).

Tugas Pemandu Lalu Lintas Udara (ATC / Air Traffic Controller) yang tercantum di dalam Annex 2 (Rules of the Air) dan Annex 11 (Air Traffic Services) Konvensi Chicago 1944 adalah mencegah tabrakan antar pesawat, mencegah tabarakan pesawat dengan obstructions, mengatur arus lintas udara yang aman, cepat dan teratur kepada pesawat udara, baik yang berada di ground atau yang sedang terbang/melintas dengan menggunakan jalur yang telah ditentukan. Untuk melaksanakan tugas tersebut diperlukan seorang petugas ATC dalam pengaturan arus lalu lintas udara yang dimulai dari pesawat melakukan komunikasi (contact) pertama kali sampai dengan pesawat tersebut mendarat (landing) di Bandar udara tujuan. Disamping itu diperlukan dukungan prasarana, sarana, serta perangkat peraturan yang sesuai dengan ketentuan-ketentuan yang dikeluarkan ICAO (International Civil Aviation Organization) atau Organisasi Penerbangan Sipil Internasional, yang dari hari ke hari terus dilakukan amandemen sesuai dengan pengembangan arus lalu lintas penerbangan dan teknologi (Air Traffic Control, Wikipedia, 2013 dan FAA, 2012).

Sebuah Menara Kontrol (Control Tower) atau lebih khusus sebagai Air Traffic Control Tower (ATCT), adalah nama dari unit ATC yang bertanggung jawab untuk pergerakan sekeliling bandara dan juga nama dari bangunan untuk unit yang mengoperasikan. Banyak Bandar udara di dunia ini yang tanpa menara atau frekuensi (mandatory frequency), hanya Bandar udara tersibuk sajalah yang mempunyai lalu lintas udara yang diatur oleh menara kontrol. Menara ATC yang permanen, mempunyai spesifikasi yang secara sistim struktur biasanya berdiri diatas bangunan lain di Bandar udara untuk memudahkan petugas pemandu lalu lintas udara (Air Traffic Controller) mengawasi pergerakan pesawat didarat dan diudara Bandar udara, walau ada juga unit menara sementara/darurat menggunakan trailer atau radio portable diluar gedung. Menara ATC secara utuh biasanya mempunyai jendela seputar lantai atas, memberikan pandangan 360 derajat bagi petugas. Plafond di ruang puncak menara (tower $c a b$ ) juga khusus dicat warna hitam. Untuk Bandar udara kelas menengah hanya mempunyai satu staff pemandu menara ATC dan tidak melayani 24 jam sehari. Sedangkan bandar udara sibuk biasanya mempunyai ruang untuk beberapa staff pemandu dan mengoperasikan 24 jam sehari, 365 hari per tahun.

Kompleksitas permasalahan terhadap pelaksanaan suatu proyek menyebabkan banyaknya proyek yang selesai tidak sesuai dengan yang direncanakan. Baik dari segi waktu, mutu dan biaya yang terkadang terjadi overbudget. Untuk mengatasi hal ini, maka perlu adanya suatu manajemen biaya, kualitas dan waktu yang baik. Manajemen yang baik adalah manajemen yang terintegrasi antara pemilik proyek, pelaksana konstruksi dan konsultan. 
Perencanaan serta pengendalian biaya dan waktu merupakan bagian dari manajemen proyek konstruksi secara keseluruhan. Selain penilaian dari segi kualitas, prestasi suatu proyek dapat pula dinilai dari segi biaya dan waktu. Biaya yang telah dikeluarkan dan waktu yang digunakan dalam menyelesaikan suatu pekerjaan harus diukur secara berkala terhadap Perencanaan dan Pelaksanaan Konstruksi. Adanya penyimpangan biaya dan waktu yang signifikan mengindikasikan pengelolaan proyek yang buruk. Dengan adanya indikator prestasi proyek dari segi biaya dan waktu ini memungkinkan tindakan pencegahan agar proyek berjalan sesuai dengan rencana, karena banyaknya proyek konstruksi yang berjalan tidak sesuai dengan yang direncanakan.

Pengendalian biaya dan waktu yang baik diharapkan dapat membantu pelaksanaan proyek sesuai dengan yang telah direncanakan. Ada beberapa metode yang dapat digunakan untuk manajemen biaya dan waktu, salah satunya dan yang akan menjadi subjek pembahasan adalah metode Analisis Nilai Hasil (Earned Value Analysis). Analisis Nilai Hasil digunakan dengan tujuan agar dapat memperkirakan (forecasting) sejauh mana proyek yang dilaksanakan sesuai dengan rencana kerja.

\subsection{Rumusan Masalah}

Berdasarkan uraian pada latar belakang masalah di atas, maka dapat dikemukakan rumusan masalah pada penelitian ini adalah sebagai berikut :

1 Bagaimana penerapan metode Analisis Nilai Hasil (Earned Value Analysis) untuk memperkirakan biaya dan waktu penyelesaian proyek setiap minggunya, apakah sesuai dengan perencanaan awal proyek ?

2 Parameter-parameter apa saja yang dominan berpengaruh terhadap biaya dan waktu pelaksanaan proyek dari analisis nilai hasil ?

3 Bagaimana Pengaruh Analisis Nilai Hasil (Earned Value Analysis) terhadap kinerja pelaksanaan proyek?

\subsection{Maksud dan Tujuan}

Berdasarkan rumusan masalah yang telah diuraikan diatas, maka tujuan yang akan dicapai dalam penelitian ini adalah sebagai berikut :

1. Mendalami penerapan metode Analisis Nilai Hasil (Earned Value Analysis) dalam memperkirakan biaya dan waktu akhir penyelesaian proyek untuk setiap minggunya terhadap rencana awal jadwal proyek, selama 32 (tiga puluh dua) minggu pelaksanaan konstruksi.

2. Merumuskan parameter yang berpengaruh terhadap biaya dan waktu pelaksanaan proyek dari analisis nilai hasil.

3. Mengsintesis Pengaruh Analisis Nilai Hasil (Earned Value Analysis) terhadap kinerja (kemajuan) pelaksanaan proyek.

\section{METODE PENELITIAN}

\subsection{Metode Penelitian}

Metode penelitian adalah langkah-langkah penelitian suatu masalah, kasus, gejala, atau fenomena dengan jalan ilmiah untuk menghasilkan jawaban yang rasional. Metode penelitian digunakan sebagai dasar atas langkah-langkah berurutan yang didasarkan pada tujuan penelitian dan menjadi suatu perangkat yang digunakan untuk menarik kesimpulan, sehingga dapat diperoleh penyelesaian yang diharapkan untuk mencapai keberhasilan penelitian.

Metode yang digunakan dalam penelitian ini adalah deskriptif kualitatif, penelitian yang menggambarkan kondisi proyek tertentu dengan analisis data-data yang ada. Analisis data menggunakan metode analisis dan deskriptif. Analisa berarti data yang sudah ada diolah 
sedemikian rupa sehingga menghasilkan akhir yang dapat disimpulkan. Sedangkan deskriptif maksudnya adalah dengan memaparkan masalah-masalah yang sudah ada atau tampak. Konsep Nilai Hasil (Earned Value Analysis) mengkaji kecenderungan varian jadwal dan varian biaya pada suatu periode waktu selama proyek berlangsung. Namun dalam penelitian ini hanya akan membahas pada varian waktu.

\subsection{Waktu dan Lokasi Penelitian}

Penelitian ini dilakukan di Bandar Udara Syukuran Aminuddin Amir, di Luwuk. Waktu penelitian di laksanakan selama 2 bulan sehingga data yang diperoleh selama waktu penelitian tersebut sudah lengkap sehingga dapat di analisis untuk memberikan jawaban atas rumusan masalah penelitian.

\subsection{Pengumpulan Data}

Untuk mendukung analisis tersebut, penulis mengambil Studi Kasus yaitu proyek Pembangunan ATC Tower Bandar Udara Syukuran Aminuddin Amir, di Luwuk. Untuk mempermudah analisis dalam penulisan ini maka diperlukan data-data yang berkaitan langsung dengan proyek tersebut.

Data-data yang dimaksud antara lain :

1. Time Schedule;

2. Rekapitulasi Biaya Anggaran Proyek;

3. Laporan Mingguan / Bulanan Proyek.

\subsection{Teknik Pengumpulan Data}

Metode pengumpulan data adalah teknik atau cara-cara yang dapat digunakan untuk pengumpulan data. Teknik dalam menunjuk suatu kata yang abstrak dan tidak diwujudkan dalam benda, tetapi hanya dapat dilihat penggunaannya melalui: angket, wawancara, pengamatan, ujian (tes), dokumentasi, dan lain-lain. Dalam penelitian dapat menggunakan salah satu atau gabungan teknik tergantung dari masalah yang dihadapi atau yang diteliti.

Kegiatan pengumpulan data dalam penelitian pada prinsipnya merupakan kegiatan penggunaan metode dan instrumen yang telah ditentukan dan diuji validitas dan reliabilitasnya. Secara sederhana, pengumpulan data diartikan sebagai proses atau kegiatan yang dilakukan peneliti untuk mengungkap atau menjaring berbagai fenomena, informasi atau kondisi lokasi penelitian sesuai dengan lingkup penelitian.

Pengumpulan data pada penelitian ini dapat dilakukan dalam berbagai sumber dan berbagai cara. Bila dilihat dari sumber datanya, maka pengumpulan data dapat menggunakan sumber primer dan sekunder. Sumber primer adalah sumber data yang langsung memberikan data kepada pengumpul data, dan sumber sekunder merupakan sumber yang tidak langsung memberikan data pada pengumpul data, misalnya lewat orang lain atau lewat dokumen. Selanjutnya kalau dilihat dari segi cara atau teknik pengumpulan data, maka teknik pengumpulan data dapat dilakukan dengan interview, kuesioner (angket), observasi. Dalam penelitian ini penulis akan menganalisis melalui Time Schedule, Rekapitulasi Biaya Anggaran Proyek, dan Laporan Mingguan / Bulanan. Data tersebut diperoleh dari Konsultan Manajemen Konstruksi yang melakukan tahapan Review Desain Perencanaan dan Pengawasan Pembangunan ATC Tower Bandar Udara Syukuran Aminuddin Amir, di Luwuk (Asep Suryana, 2007).

\section{ANALISA DATA}

\subsection{Konsep Analisis Nilai Hasil (Earned Value)}

Hasil perhitungan proyek Pembangunan ATC Tower Bandara Syukuran Aminuddin Amir di Luwuk, telah didapatkan data yang dapat dipergunakan untuk mengetahui keadaan proyek saat evaluasi proyek. Perhitungan proyek Pembangunan ATC Tower Bandara Syukuran Aminuddin Amir di Luwuk menunjukkan Varian waktu dan biaya yang terjadi pada proyek, sehingga metode konsep analisis nilai hasil dapat memantau pekerjaan, serta 
memperlihatkan penyimpangan yang dapat terjadi pada biaya serta waktu pelaksanaan pada proyek yang dapat dilihat pada kurva penyajian, sehingga menjadi alat pembuktian yang akurat. Hasil perhitungan indikator-indikator konsep analisis nilai hasil dapat memberikan peringatan dini pada pelaksana untuk melakukan tindakan-tindakan pencegahan dan preventif untuk mencegah terjadi penyimpangan hingga proyek berakhir.

\subsection{Angka Varian}

Angka varian terdiri dari varian biaya dan varian jadwal, dalam analisis ini menggunakan indikator PV dan EV untuk menentukan varian jadwal.

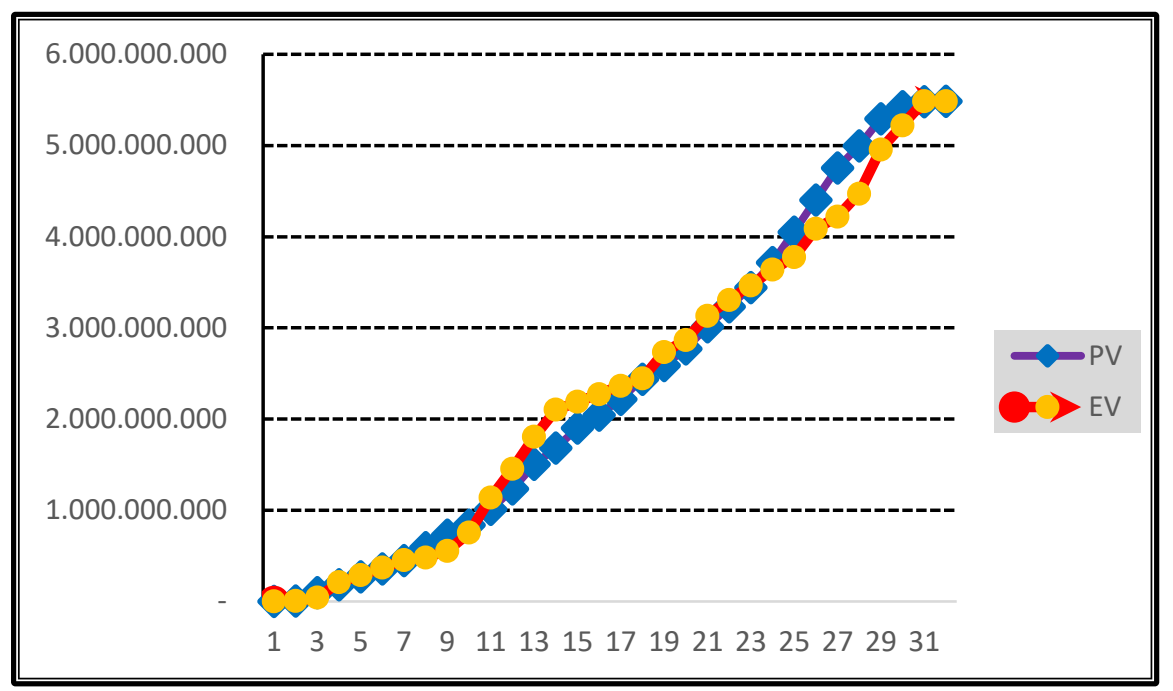

Gambar 1. Perbandingan Planned Value (PV) dan Earned Value (EV)

Gambar 1. menunjukkan perbandingan nilai PV dan EV. Minggu ke - 1 hingga minggu ke 7 menunjukkan bahwa nilai PV dan EV sejajar, lalu minggu ke - 8 sampai minggu ke - 10 nilai PV lebih besar daripada EV, kemudian Minggu ke - 11 hingga minggu ke - 23 grafik EV lebih tinggi dari PV, lalu untuk minggu ke - 24 hingga minggu ke - 30 nilai PV lebih besar daripada EV dan nilai pekerjaan pada Minggu ke - 31 sampai 32 terhitumg sudah selesai $100 \%$. Hal ini memperlihatkan pada minggu ke - 1 hingga minggu ke -7 nilai EV dan PV berada dalam garis yang sama menunjukkan bahwa item pekerjaan yang seharusnya dikerjakan menurut time schedule telah dikerjakan tepat waktu, namun pada minggu ke - 8 hingga minggu ke - 10 terjadi perlambatan kemajuan pekerjaan yang diakibatkan belum tersedianya sumber daya material di lokasi proyek, lalu pada Minggu ke - 11 hingga minggu ke - 23 pekerjaan mengalami kemajuan lalu melambat lagi pada minggu ke - 24 hingga 30 dan selesai sesuai dengan schedule awal (PV) pada minggu ke - 32.

\subsection{Varian Jadwal}

Hasil perhitungan Varian jadwal (SV) pada proyek Pembangunan ATC Tower Bandara Syukuran Aminuddin Amir di Luwuk, tidak selalu bernilai positif dan indeks produktivitasnya tidak selalu bernilai 1 pada tiap minggunya, seperti yang terlihat pada minggu ke -9 sebesar :

$$
\begin{array}{ll}
\text { Varian Jadwal (SV) } & =\text { Rp. }-173.522 .807,00 \\
\text { Indeks produktivitas jadwal (SPI) } & =0.53
\end{array}
$$

Nilai SV minggu ke-9 adalah negatif, dan nilai SPI minggu ke - 9 kurang dari 1, maka pekerjaan pada minggu ke - 9 mengalami keterlambatan atau waktu pelaksanaan lebih lama dari yang direncanakan. 


\subsection{Angka Proyeksi Waktu Akhir}

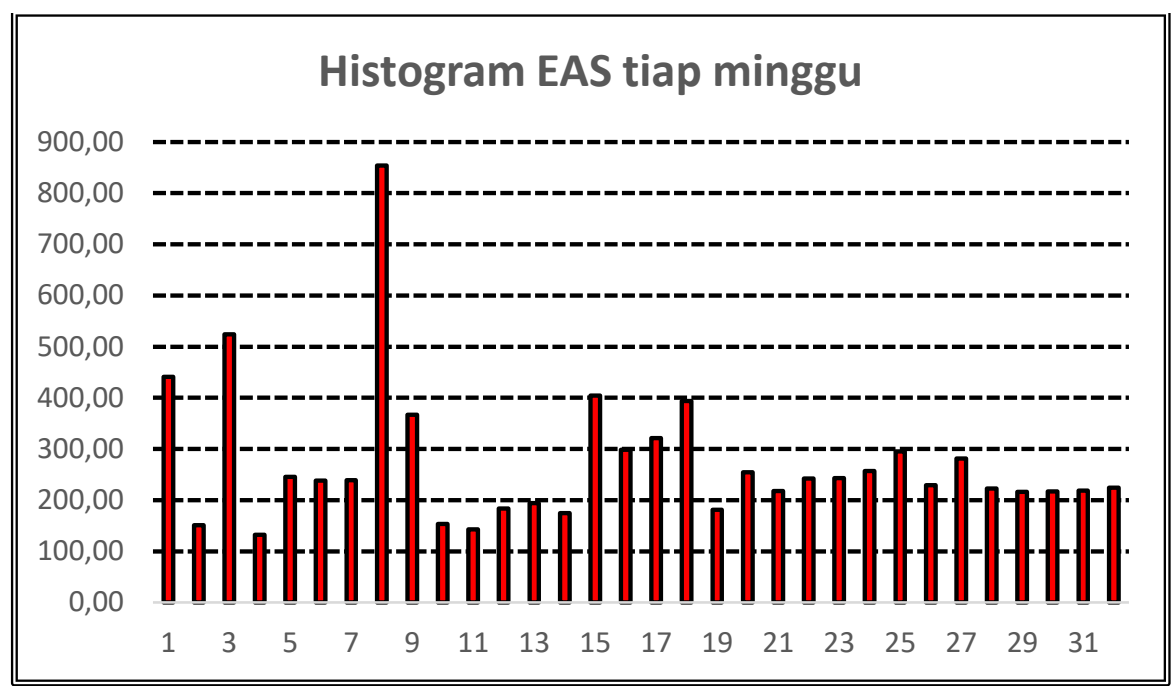

Gambar 2. Histogram EAS tiap minggu

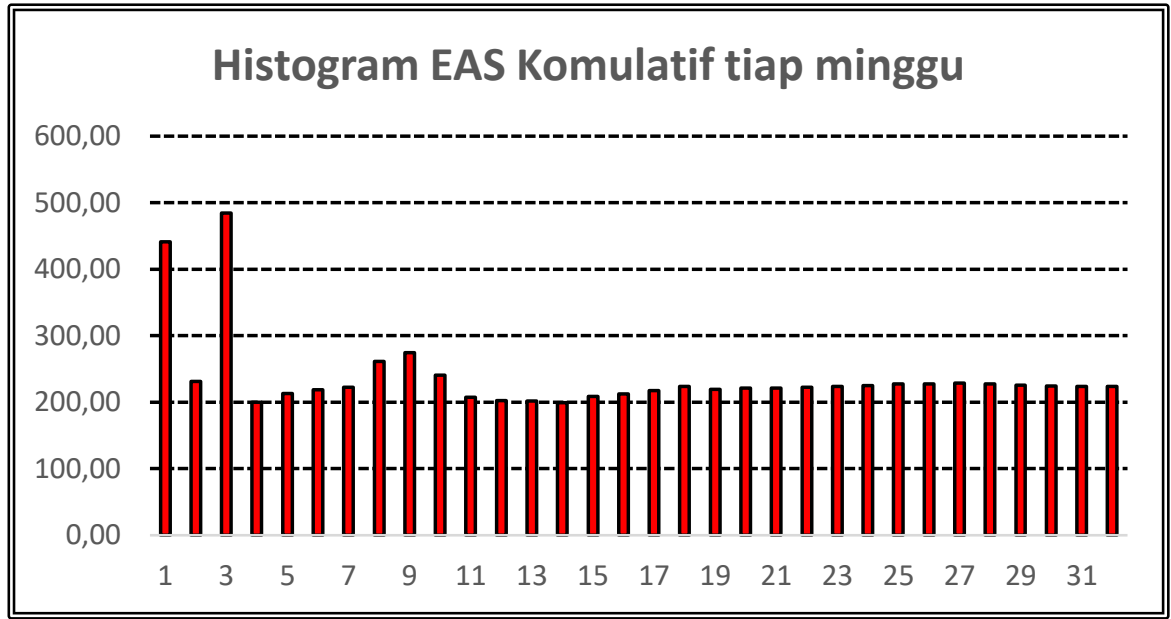

Gambar 3. Histogram EAS Komulatif tiap minggu

1. Prakiraan waktu penyelesaian proyek

EAS minggu ke - 7

Nilai EAS minggu ke - 7 di dapat dari rumus 2.11

Sisa waktu $\quad=175$ hari

Waktu selesai $\quad=49$ hari

SPI $\quad=0,92$

ETS $\quad=($ sisa waktu $) /$ SPI

$=175 / 0,92$

$=190,36$ hari

EAS $\quad=$ Waktu selesai + ETS

$=49+190,36$

$=239,36$ hari

Selisih waktu $\quad=$ waktu rencana pelaksanaan - EAS

$=224$ hari $-239,36$ hari

$=-15,36$ hari

2. Prakiraan waktu penyelesaian proyek

EAS minggu ke -7 secara komulatif 


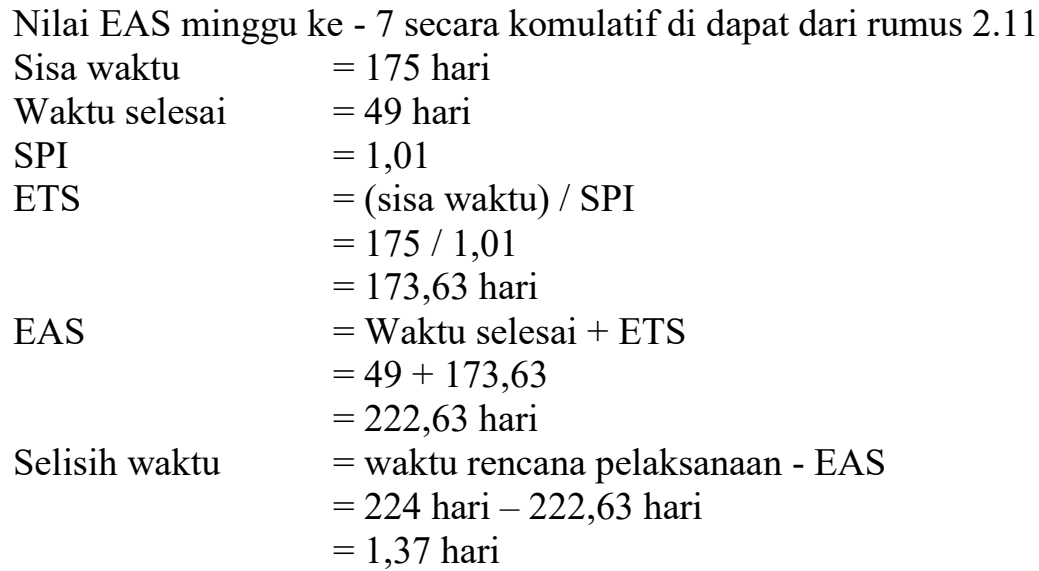

Prakiraan waktu penyelesaian proyek apabila menggunakan perhitungan komulatif, berdasar minggu ke - 7 adalah 222.63 hari (14 April 2019), sedangkan waktu rencana adalah 224 hari (15 April 2019). Hal ini menunjukkan bahwa waktu penyelesaian lebih cepat 1.37 hari dari yang direncanakan. Sedangkan apabila kita menggunakan perhitungan tiap minggu, Prakiraan waktu penyelesaian proyek berdasar minggu ke - 7 adalah 239,36 hari (30 April 2019), sehingga proyek mengalami keterlambatan - 15,36 hari.

Pada Tabel 4.15. dapat dilihat bahwa setelah minggu ke-6, pada tiap minggunya pekerjaan mengalami keterlambatan. Salah satu penyebab keterlambatan adalah tingkat produktivitas tenaga kerja yang rendah (presentase penyelesaian pekerjaan kecil) dan manajemen yang kurang baik, maka prakiraan waktu penyelesaian proyek menjadi lebih lama dan hal ini mengakibatkan keterlambatan pada pekerjaan lain yang mengikutinya.

\subsection{Pengaruh Analisis Nilai Hasil Terhadap Kinerja Proyek}

Berdasarkan analisis yang telah dilakukan terhadap penerapan metode analisis nilai hasil pada biaya dan waktu pelaksanaan proyek Pembangunan ATC Tower Bandar Udara Syukuran Aminuddin Amir, di Luwuk, maka dapat disimpulkan bahwa :

1. Metode Analisis Nilai Hasil dapat menjadi sarana deteksi dini terhadap metode kerja, masalah dalam perencanaan dan penjadwalan, tata letak dan pengelolaan material, pemberian penghargaan pada kepuasan kerja, pemberian insentif, pemberian kerja lembur dan pemogokan kerja karena alasan tertentu;

2. Dengan menerapkan Metode Analisis Nilai Hasil, maka secara periodik dapat dilakukan penyesuaian terhadap Perubahan urutan kerja dalam pelaksanaan proyek, manajemen pengawasan tenaga kerja, komunikasi dan hubungan kerja, untuk memperoleh kinerja terbaik dari pelaksanaan proyek;

3. Metode Analisis Nilai Hasil dapat mengatur Kesesuaian kebutuhan terhadap penggunaan material dan alat, lingkungan fisik lapangan, operator alat berat di lapangan, keselamatan dan kesehatan kerja di lapangan;

4. Dengan menerapkan Metode Analisis Nilai Hasil maka tingkat / standar upah tenaga kerja dilokasi proyek dapat disesuaikan dengan perhitungan biaya dan sisa waktu pelaksanaan proyek.

\section{KESIMPULAN}

Hasil analisis dengan menggunakan Metode Analisis Nilai Hasil Terhadap Biaya dan Waktu pada Pembangunan ATC Tower Bandar Udara Syukuran Aminuddin Amir, di Luwuk adalah:

1. Minggu ke - 1 hingga minggu ke - 7 menunjukkan bahwa nilai PV dan EV sejajar, lalu minggu ke - 8 sampai minggu ke - 10 nilai PV lebih besar daripada EV, kemudian Minggu ke - 11 hingga minggu ke - 23 grafik EV lebih tinggi dari PV, lalu untuk minggu ke - 24 hingga 
minggu ke - 30 nilai PV lebih besar daripada EV dan nilai pekerjaan pada Minggu ke - 31 sampai 32 terhitumg sudah selesai $100 \%$. Prakiraan waktu penyelesaian proyek apabila menggunakan perhitungan komulatif, berdasar minggu ke - 7 adalah 222.63 hari (14 April 2019), sedangkan waktu rencana adalah 224 hari (15 April 2019). Hal ini menunjukkan bahwa waktu penyelesaian lebih cepat 1.37 hari dari yang direncanakan. Sedangkan apabila kita menggunakan perhitungan tiap minggu, Prakiraan waktu penyelesaian proyek berdasar minggu ke - 7 adalah 239,36 hari (30 April 2019), sehingga proyek mengalami keterlambatan - 15,36 hari. Kemudian, biaya pelaksanaan proyek berdasar nilai kontrak Rp. 5,484,489,072 sedangkan total biaya pelaksanaan proyek berdasar analisis nilai hasil (earned value) sebesar Rp. 4,661,815,711 sehingga terdapat keuntungan kotor sebesar Rp. 822,673,361.;

2. Parameter-parameter yang berpengaruh terhadap biaya dan waktu pelaksanaan proyek berdasarkan konsep analisis nilai hasil antara lain :

A. BCWS (Budgeted Cost Work Schedule)

Budgeted Cost Work Schedule merupakan Analisa Anggaran yang dimiliki oleh proyek sesuai dengan inventarisasi kegiatan yang dihitung berdasarkan prosentase terhadap biaya total, sesuai data lapangan selama 32 minggu. BCWS dihitung dengan menggunakan rumus yaitu :

BCWS $=(\%$ Bobot Rencana $) \times($ Total Anggaran $)$

B. BCWP (Budgeted Cost Work Performed)

Budgeted Cost Work Performed merupakan biaya yang dianggarkan dari pekerjaan yang diselesaikan oleh pelaksana, BCWP dapat dihitung dengan menggunakan rumus yaitu :

$\mathrm{BCWP}=(\%$ Bobot Pelaksanaan $) \times($ Total Anggaran $)$

C. ACWP (Actual Cost Work Performance)

Actual Cost Work Performance atau Biaya Aktual merupakan nilai biaya yang sebenarnya dikeluarkan untuk pekerjaan yang telah terlaksana, ACWP dapat dihitung dengan menggunakan rumus yaitu :

$\mathrm{ACWP}=(\%$ Bobot Pelaksanaan $) \mathrm{x}($ Total Biaya Pelaksanaan $)$

3. Pengaruh Analisis Nilai Hasil (Earned Value Analysis) terhadap kinerja pelaksanaan proyek menghasilkan perhitungan pelaksanaan proyek Pembangunan ATC Tower Bandar Udara Syukuran Aminuddin Amir, di Luwuk, maka data yang dipergunakan untuk mengetahui keadaan proyek saat evaluasi proyek. Perhitungan kinerja proyek pembangunan ATC Tower Bandar Udara Syukuran Aminuddin Amir, di Luwuk menunjukkan varians waktu dan biaya yang terjadi pada proyek, sehingga metode konsep analisis nilai hasil dapat memantau pekerjaan, serta memperlihatkan apabila terjadi penyimpangan terhadap waktu dan biaya pada proyek yang dapat dilihat pada kurva penyajian, sehingga menjadi alat pembuktian yang akurat. Hasil perhitungan indikator-indikator konsep nilai hasil dapat memberikan peringatan dini pada pelaksana untuk melakukan tindakan koreksi yang akan dilakukan untuk mencegah terjadi penyimpangan hingga proyek berakhir.

\section{SARAN}

1. Untuk analisis yang lebih mendetail mengenai kebutuhan sumber daya tenaga ahli dan material, maka pada penelitian yang seperti ini bisa menggunakan POM-QM Windows dengan 29 Modul, QS 8+, Microsoft Project atau Primavera;

2. Penerapan Metode Analisis Nilai Hasil, sudah harus diterapkan pada saat awal pelaksanaan proyek untuk dapat melakukan control dan deteksi dini terhadap bahaya over budgeting dan keterlambatan pelaksanaan proyek;

3. Untuk menyempurnakan kinerja Metode Analisis Nilai Hasil yang sifatnya makro, maka sebaiknya menambahkan metode - metode pelaksanaan proyek yang bersifat mikro seperti Critical Path Methode (CPM), Hungarian Methode, Dll yang sesuai dengan tahapan pelaksanaan pekerjaan, yang bertujuan untuk optimalisasi terhadap kinerja biaya dan waktu pelaksanaan proyek. 


\section{UCAPAN TERIMA KASIH}

Dalam pembuatan penulisan ini mampu terwujud berkat adanya arahan dan bimbingan dari berbagai pihak. Oleh karena itu dengan segala ketulusan dan kerendahan hati, kami mengucapkan terima kasih dan penghargaan yang setinggi-tingginya kepada pembimbing I dan pembimbing II yang telah berkenan memberikan bimbingan dan arahan serta menyediakan waktunya untuk berdiskusi dalam penyusunan tesis ini, Bapak dan Ibu dosen serta staf pegawai pada program studi magister, Ayahanda dan ibunda tercinta yang senantiasa memberikan limpahan kasih sayang dan Rekan-rekan mahasiswa magister teknik sipil Fakultas Teknik.

\section{UCAPAN TERIMA KASIH}

Airnav Indonesia, 2019, Laporan Akhir Pembangunan ATC Tower di Luwuk; LPPNPI. Asiyanto, 2005. Manajemen Produksi Untuk Jasa Konstruksi, Jakarta : Penerbit Pradnya Paramita, Cetakan Pertama.

Atsaruddin, Achmad Taris, 2015. Perbandingan Rencana Anggaran Biaya Rumah MPanel dengan Rumah Konvensional Proyek Pembangunan Rumah Tipe 60/99 Pondok Permata Suci Gresik, Malang : Universitas Brawijaya.

Adjei, Emmanuel A-G, 2018. Exploring the Significant Cash Flow Factors Influencing Building Projects Profitability in Ghana, United Kingdom : Birmingham City University.

Anuar, N. I. and Poh kiat $\mathrm{Ng}$, , 2014, The role of time, cost and quality in project management, Malaysia: Centre of diploma programme, multimedia university.

Baker, J. Ester, D, Valsa, S. and Riccardo, P, 2013, How to Define and Measure Value for Money in the Humanitarian Sector, sweden: Citat.

Barrie, D.S, 1995, Manajemen Konstruksi Profesional, Jakarta : Penerbit Erlangga.

Cleland, D. L, 1995, Project Management Strategic Design and Implementation, Singapore : Mc. Graw-Hill, Inc.

Creswell, J. W., 2009, research design; Qualitative, Quantitative, and Mixed Methods Approaches 3rd ed, Singapore: SAGE Publication Inc.

http://manajemenproyekindonesia.com/?p=769

https://proyeksipil.blogspot.com/2017/03/cara-menentukan-lama-waktupelaksanaan.html

http://irikakuliah.blogspot.com/2011/05/metode-nilai-hasil-earnedvalue.htmlPendahuluan

Maromi, Muhammad Izeul, 2015. Metode Earned Value untuk Analisa Kinerja Biaya dan Waktu Pelaksanaan pada Proyek Pembangunan Condotel De Vasa Surabaya, Surabaya : Institut Teknologi Sepuluh November.

Messah, Yunita Alfiana, 2013. Pengendalian Waktu dan Biaya Pekerjaan Konstruksi Sebagai Dampak Dari Perubahan Desain, Kupang : Universitas Nusa Cendana.

PMBOK guide (A Guide to the Project Management Body of Knowledge), 2004, Third Edition.

Prastyono, Hendra Galih, 2010. Earned Value Analysis pada Proyek Pembangunan Gedung (Studi kasus Proyek Pembangunan Gedung C Fakultas MIPA UNS) : Surabaya, Universitas Airlangga.

Radujkovic, Mladen, 2017. Project Management Success Factors, Primosten, Croatia : Elsevier.

Sakinah, Baiq Farida, 2015. Analisis Penyebab Keterlambatan pada Pekerjaan Konstruksi Jalan Kabupaten Lombok Tengah dengan Metode Analisa Faktor, Malang : Universitas Brawijaya.

Simaya, Happy, 2018. Assessment of the Performance of Value for Money for Building Projects in Local Government Authorities in Tanzania, Dar es Salaam, Tanzania: 
Ardhi University.

Sufa'atin, 2017. Penerapan Metode Earned Value Management (EVM) dalam Pengendalian Biaya Proyek, Bali : Universitas Udayana.

Sudarsana, Dewa Ketut. 2008. Pengendalian biaya dan jadual terpadu pada proyek konstruksi, Bandung: UNIKOM

Soeharto, Iman, 1997, Manajemen Proyek Dari Konseptual Sampai Operasional, Jakarta : Penerbit Erlangga.

Suryana, Asep, 2007. Tahap-Tahapan Penelitian Kualitatif, Jakarta : Universitas Pendidikan Indonesia

Wijoyo, Agung Nira, 2015. Analisis Biaya pada Pembangunan Gedung Bertingkat di Kabupaten Tulungagung dari Struktur Balok yang Dilaksanakan Terhadap yang Dipersyaratkan, Malang : Universitas Brawijaya. 